\title{
Boron removal by membrane contactors: the water that purifies water
}

\author{
A. Criscuoli $\cdot$ E. Rossi $\cdot$ F. Cofone $\cdot$ E. Drioli
}

Published online: 25 July 2009

(C) Springer-Verlag 2009

\section{Erratum to: Clean Techn Environ Policy \\ DOI 10.1007/s10098-009-0221-8}

\section{Additional information}

It should be noticed that, even when considering the performance obtained at lab scale $(9 \%$ of removal in $5 \mathrm{~h}$ with the M1 membrane), the proposed flowsheet is still characterised by no use of chemicals and lower energy consumptions, higher flexibility and modularity than the traditional one.

The lower removal only implies the use of higher membrane areas for performing the target separation $\left(25,250 \mathrm{~m}^{2}\right.$ are required for reducing the boron content down to $0.36 \mathrm{ppm}$ by membrane contactors) and, consequently, an increase of the size. The productivity/size ratio is, however, close to 1 ( $\mathrm{PS}=0.92$ ).

The online version of the original article can be found under doi:10.1007/s10098-009-0221-8.

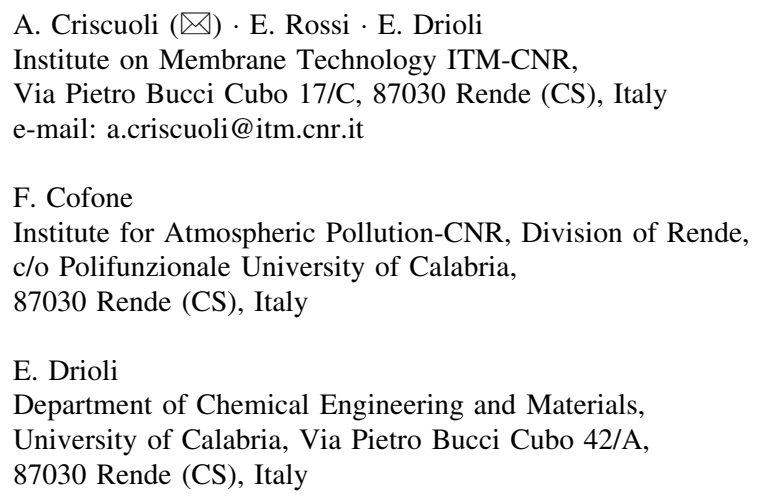

